\title{
História e situação da agricultura e do desenvolvimento rural em quatro municípios do noroeste do Rio Grande do Sul
}

Edmundo Hoppe Oderich ${ }^{1}$ Lovois de Andrade Miguel ${ }^{2}$

\begin{abstract}
Resumo
Este trabalho reconstitui as principais etapas da evolução da agricultura no norte do Médio Alto Uruguai, no Rio Grande do Sul, colocando em evidência as particularidades da realidade agrária desta região. A delimitação geográfica do estudo compreende o território atualmente pertencente aos municípios de Frederico Westphalen, Iraí, Caiçara e Vicente Dutra. Buscou-se evidenciar condicionantes naturais e históricos que explicassem objetivamente a evolução da agricultura desta região, de modo a explicitar suas particularidades e a atual situação de estagnação da agricultura local. O estudo compreende três partes distintas. Primeiramente, foi realizada uma contextualização socioeconômica da região de estudo, atentando para aspectos ligados à agricultura. Em seguida, são expostos aspectos edafoclimáticos desta região, com importante influência no desenvolvimento da agricultura. Por fim, apresenta-se a evolução e diferenciação dos sistemas agrários no território abrangido pelos municípios em questão, destacando-se as principais etapas e particularidades do desenvolvimento da agricultura local.
\end{abstract}

Palavras-chave: História da Agricultura. Sistemas Agrários. Desenvolvimento Rural. Alto Uruguai. Rio Grande do Sul.

\section{Abstract}

This paper retraces the main stages of the agriculture evolution in the north Médio Alto Uruguay, in Rio Grande do Sul, highlighting the particularities of the agrarian reality of this region. The geographical scope of this study comprises the territory currently belonging to the municipalities of Frederico Westphalen, Irai, Caiçara and Vicente Dutra. The aim was to highlight the natural and historical conditions that objectively explain the development of agriculture in this region in order to clarify its particularities and its current stagnation situation. The study comprises three distinct parts. At first, a socio-economic contextualization of the region of

\footnotetext{
${ }^{1}$ Engenheiro Agrônomo, Mestre e doutorando em Desenvolvimento Rural pelo Programa de Pós-Graduação em Desenvolvimento Rural (PGDR/UFRGS). Extensionista Rural de Nível Superior na ASCAR/EMATER-RS. edmundo1234@gmail.com

2 Engenheiro Agrônomo, Doutor em Desenvolvimento Rural. Professor do Programa de Pós-Graduação em Desenvolvimento Rural (PGDR/UFRGS). lovois@ufrgs.br
} 
study was made, paying attention to agriculture related aspects. Then edaphoclimatic aspects of this region are exposed, with important influence in agriculture development. Finally, the evolution and differentiation of agricultural systems in the territory covered by the municipalities in question was made, highlighting the main stages and particularities of the local agriculture development.

Keywords: Agriculture History. Agrarian Systems. Rural Development. Alto Uruguay. Rio Grande do Sul.

\section{Introdução}

Os municípios de Frederico Westphalen, Iraí, Caiçara e Vicente Dutra apresentam uma série de particularidades e especificidades no que tange à situação agrária atual. Tendo como referência local o município de Frederico Westphalen, esses municípios estão situados no Corede Médio Alto Uruguai ${ }^{3}$, região que compreende 22 municípios do noroeste do Rio Grande do Sul (Figura 1). Esta região apresenta características socioeconômicas bastante peculiares, destoando da realidade agrária do restante do Estado do Rio Grande do Sul em diversos aspectos.

\section{Figura 1 - Localização dos municípios de Caiçara, Vicente Dutras, Iraí e Frederico Westphalen}

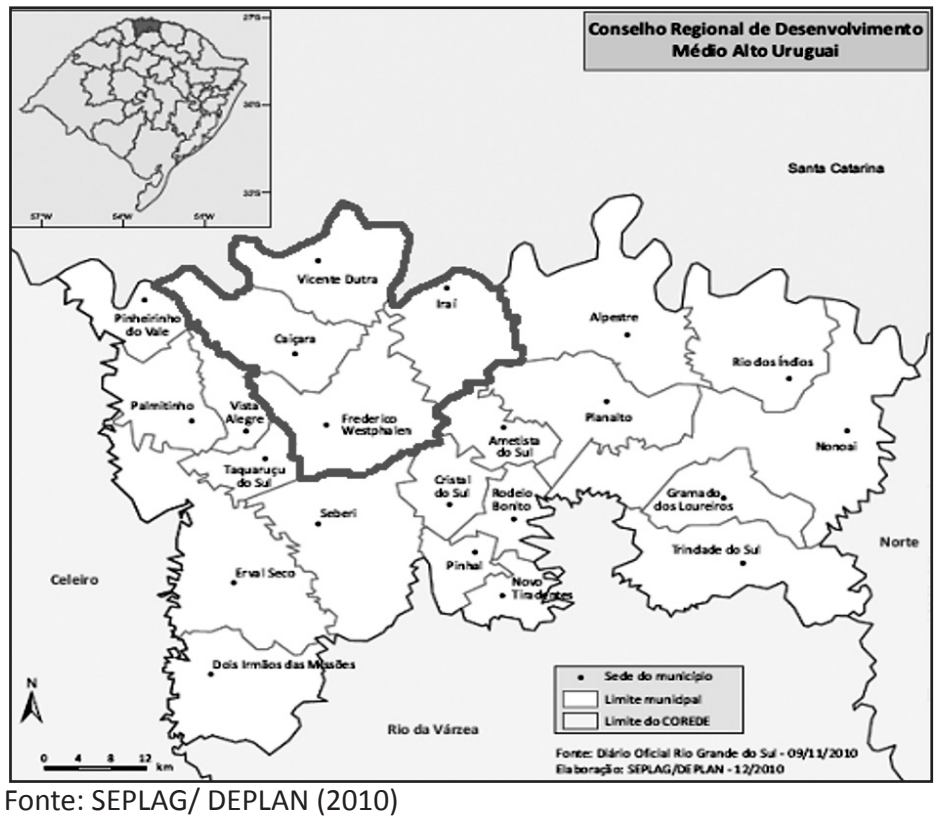

${ }^{3}$ Os Conselhos Regionais de Desenvolvimento (Coredes) constituem uma divisão políticoadministrativa do Rio Grande do Sul em 28 regiões, proposta pela Fundação de Economia e Estatística do Rio Grande do Sul (FEE). 
Primeiramente, cabe salientar que esta região se destaca por apresentar um elevado índice de população residente no meio rural, ultrapassando 50\%, segundo Conterato e Schneider (2006). A estrutura fundiária é fortemente marcada pela hegemonia e amplo predomínio da pequena propriedade de cunho familiar. Segundo o Censo Agropecuário (IBGE, 2006), 95\% dos estabelecimentos da microrregião de Frederico Westphalen ${ }^{4}$ possuem menos de 50 hectares, ocupando $70 \%$ da área, enquanto irrisórios 0,14\% dos estabelecimentos possuem mais de 500 hectares, ocupando apenas $7 \%$ da área. Igualmente, esta região apresenta elevados índices de pobreza.

O Índice de Desenvolvimento Econômico e Social (IDESE ${ }^{5}$ ) do Corede Médio Alto Uruguai apresentou o valor mais baixo no comparativo entre os 28 Coredes do Rio Grande do Sul, com destaque para os indicadores de renda, saneamento e educação (FEE, 2009). Cabe salientar que, segundo Carneiro (2011), o Médio Alto Uruguai tem apresentado crescimento empobrecedor, especialmente nos municípios predominantemente rurais, contribuindo para o elevado índice de pobreza rural. Destaca-se ainda o fato de que o Médio Alto Uruguai está entre as treze regiões mais pobres do país (FEPAM, 2012). Identifica-se, igualmente, nesta região uma elevada taxa de analfabetismo. Segundo Conterato, Gazolla e Schneider (2007), em 2004, a região do Médio Alto Uruguai contava com 12,7\% de analfabetos, quase o dobro da média rio-grandense de 6,7\% em 2000 (RS, 2011). O percentual se eleva a $28,7 \%$ quando se trata da população rural da região (CONTERATO; SCHNEIDER; WAQUIL, 2008). Também são constatados índices negativos de crescimento populacional na maioria dos municípios da região, em especial os rurais, configurando um processo de envelhecimento da população rural e esvaziamento da região como um todo (RS, 2011).

Paradoxalmente, esta região se caracteriza por apresentar um elevado grau de associativismo entre os agricultores. Segundo Conterato e Schneider (2006), na década de 90, mais da metade dos agricultores da microrregião de Frederico Westphalen apresentava vínculo com algum tipo de cooperativa, de modo a garantir vantagens principalmente na comercialização de sua produção. Por fim, identifica-se uma baixa ocorrência de motomecanização agrícola. Segundo o Censo Agropecuário (IBGE, 2006), nos quatro municípios foco deste trabaIho, apenas $17 \%$ dos estabelecimentos agropecuários possuem tratores, a grande maioria com potência inferior a $100 \mathrm{CV}$.

O conjunto das situações e particularidades elencadas acima, somado a outras que poderiam ser acrescentadas, revela a importância de compreender as origens desta situação para que se possa superar o delicado período atravessado pela região. Por se tratar de uma região predominantemente rural, na qual as atividades ligadas à agricultura ocupam papel preponderante na economia e

\footnotetext{
${ }^{4}$ A microrregião de Frederico Westphalen é uma delimitação geográfica do IBGE, diferindo da utilizada pela FEE. No entanto, ambas têm a maioria dos municípios em comum.

5 Índice de Desenvolvimento Socioeconômico desenvolvido pela Fundação de Economia e Estatística do Rio Grande do Sul (FEE), que avalia quatro indicadores econômicos e sociais: renda, saúde, educação e saneamento e domicílio.
} 
nas relações sociais, torna-se ainda mais importante uma análise que considere a complexidade das realidades agrárias, examinando os fatores naturais e histórico-culturais que moldaram a evolução da agricultura na região no passado e continuarão a fazê-lo no futuro.

\section{Caracterização geomorfoambiental}

A região de Médio Alto Uruguai está situada ao norte do Planalto Meridional Sul-Riograndense. Os municípios de Caiçara, Frederico Westphalen, Iraí e Vicente Dutra ocupam um território de $831 \mathrm{~km}^{2}$ e estão localizados às margens do Rio Uruguai. Diferentemente de outras regiões de maior altitude do Médio Alto Uruguai, mais afastadas da margem do rio, a região ocupada por estes municípios apresenta um relevo ondulado a fortemente ondulado, com presença de afloramentos rochosos. No município de Iraí - o mais plano entre os quatros municípios - somente $27 \%$ das terras são planas, aptas para culturas anuais, enquanto os $73 \%$ restantes são formados por terras declivosas, apresentando, portanto, algum nível de restrição para a prática da agricultura. Baseados nessas informações e nas imagens georreferenciadas fornecidas pela Embrapa (2005), é possível inferir que a área ocupada pelos quatro municípios apresenta aproximadamente $20 \%$ de terras planas, aptas para culturas anuais, indicando o relevo como limitador natural da agricultura nesse território.

Em relação aos solos, identifica-se a ocorrência de uma associação entre Neossolos Regolíticos, Cambissolos Háplicos - ambos eutróficos - e Luvissolos Háplicos. De modo geral, são solos de boa fertilidade natural, intercalando-se ao longo da paisagem em função do relevo. Frequentemente são solos rasos e pedregosos, implicando em restrições para a mecanização. Cabe salientar, conforme descrito por Streck et al. (2008, p. 60-61), que os cambissolos desta região "[...] provavelmente são Chernossolos Argilúvicos degradados pelo intenso uso agrícola", o que resultou na erosão das características originais deste último. Os autores ainda destacam que "[...] este fato chama a atenção para os efeitos significativos da atividade humana (através do uso e manejo) na modificação das características dos solos" (STRECK et al., 2008, p. 61).

O clima da região é classificado como subtropical úmido com verões quentes ${ }^{6}$. Apesar das estiagens esporádicas, a precipitação pluvial é abundante (em torno de $1900 \mathrm{~mm}$ anuais) e distribui-se uniformemente ao longo do ano (MATZENAUER et al. 2007). Quanto à vegetação, a elevada disponibilidade hídrica associada à temperatura média da região proporcionou a formação de florestas relativamente densas, típicas do Bioma Mata Atlântica, no qual a região do Médio Alto Uruguai está inserida. Originalmente, a formação vegetal no território ocupado pelos quatro municípios era composta por uma associação entre Floresta Estacional Decidual e Floresta Ombrófila Mista (ou Floresta de Araucária). Contudo, devido à expansão da agricultura, segundo dados do Censo Agropecuário

\footnotetext{
${ }^{6} \mathrm{~A}$ temperatura média do ar, no mês mais quente, é igual ou superior a $22{ }^{\circ} \mathrm{C}$.
} 
(IBGE, 2006), menos de $15 \%$ da área agrícola dos quatro municípios estudados encontram-se atualmente ocupados por florestas (naturais ou plantadas).

Por fim, pode-se destacar a elevada distância, do ponto de vista geográfico, desses municípios em relação aos principais centros econômicos e demográficos do Rio Grande do Sul. Portanto, a localização geográfica desta região acarretou relevantes dificuldades no que tange ao transporte, ao comércio e à comunicação com as regiões economicamente mais dinâmicas.

\section{Principais etapas da evolução da agricultura}

As principais etapas da evolução e diferenciação da agricultura da região são identificadas e descritas a partir do referencial teórico da abordagem de sistemas agrários. Segundo essa abordagem, um sistema agrário pode ser definido como sendo:

[...] a expressão teórica de um tipo de agricultura historicamente constituído e geograficamente localizado, composto de um ecossistema característico e de um sistema social produtivo definido, permitindo explorar duradouramente a fertilidade do ecossistema cultivado (MAZOYER; ROUDART, 2001, p. 43).

De antemão, cabe ressaltar que não se trata de abordar e restituir todos os aspectos, detalhes e especificidades pouco representativas da região de estudo. Também é oportuno relembrar que a agricultura evolui de forma contínua, dialética, com idas e vindas, numa constante adaptação e acúmulo de conhecimentos produzidos pelo ser humano sobre o ambiente no qual está inserido. Sendo assim, a tentativa de sintetizar a evolução da agricultura da região em grandes etapas está longe - tampouco se pretende isso - de esgotar todas as particularidades, riqueza e diversidade de situações que tomaram lugar ao longo da história.

Da mesma forma, as divisões temporais dos sistemas agrários identificados e caracterizados não podem ser encaradas como divisores estanques, servindo apenas para uma orientação geral acerca dos diferentes momentos históricos. Como será mostrado, em cada novo sistema agrário, permanecem traços dos anteriores. Pretende-se, assim, identificar as características essencialmente distintas nessas grandes etapas da história da agricultura na região, descrevendo as tendências evolutivas mais gerais, os principais fatos históricos, bem como fatores que desencadearam crises e transformações.

A reconstituição das diferentes formas de agricultura neste território, ao longo da história, permitiu identificar quatro sistemas agrários distintos. No Quadro 1 (na próxima página), são apresentados, de maneira sintética, os diferentes sistemas agrários que se sucederam ao longo da história, assim como as suas principais características e particularidades. 
As formas de agricultura mais antigas identificáveis no sudeste da América Latina eram praticadas por povos indígenas. Segundo Miguel (2009), no território atualmente ocupado pelo Rio Grande do Sul, registros indicam que, na época da chegada dos europeus esta região era habitada por dois grandes grupos étnicos distintos: os Gês e os Tupi-Guaranis. Especificamente na região do Médio Alto Uruguai predominavam tribos indígenas Caigangues, originárias dos Gês.

Para garantir sua sobrevivência, esses primeiros habitantes do Médio Alto Uruguai obtinham boa parte de seus alimentos através da caça, da pesca, da coleta de frutas silvestres, erva mate, pinhão, mel, entre outros. Esses alimentos eram complementados por outros, como milho, mandioca, inhame, batata-doce e feijão, cultivados por meio de uma agricultura manual, sobre a qual as tribos já dispunham de um significativo conhecimento.

\section{Quadro 1 - Evolução dos Sistemas Agrários nos Municípios de Frederico Westphalen, Caiçara, Iraí, Vicente Dutra}

\begin{tabular}{|c|c|c|c|c|}
\hline $\begin{array}{l}\text { Período } \\
\text { Variáveis }\end{array}$ & $\begin{array}{l}\text { Sistema } \\
\text { Indígena } \\
\text { (até1890) }\end{array}$ & $\begin{array}{c}\text { Sistema Caboclo } \\
(1890-1930)\end{array}$ & $\begin{array}{c}\text { Sistema } \\
\text { Colonial } \\
(1930-1970)\end{array}$ & $\begin{array}{l}\text { Sistema Atual } \\
\text { (a partir de } \\
\text { 1970) }\end{array}$ \\
\hline Vegetação & $\begin{array}{l}\text { Basicamen- } \\
\text { te floresta } \\
\text { primária. }\end{array}$ & $\begin{array}{l}\text { Floresta primária; } \\
\text { área irrisória de } \\
\text { vegetação pio- } \\
\text { neira, secundária } \\
\text { ou cultivada. }\end{array}$ & $\begin{array}{l}\text { Aceleração da } \\
\text { substituição } \\
\text { de áreas de } \\
\text { florestas por } \\
\text { lavouras. }\end{array}$ & $\begin{array}{l}\text { Predomínio de } \\
\text { lavouras anuais } \\
\text { e pastagens; } \\
\text { Floresta primária } \\
\text { insignificante. }\end{array}$ \\
\hline $\begin{array}{l}\text { Principais } \\
\text { atividades } \\
\text { agrícolas }\end{array}$ & $\begin{array}{l}\text { Caça, pesca } \\
\text { e coleta } \\
\text { (erva mate, } \\
\text { pinhão, fru- } \\
\text { tas, mel); } \\
\text { Agricultura } \\
\text { de coivara } \\
\text { (milho, inha- } \\
\text { me, feijão, } \\
\text { mandioca, } \\
\text { batata } \\
\text { doce). }\end{array}$ & $\begin{array}{l}\text { Agricultura de } \\
\text { subsistência; } \\
\text { Coleta de erva } \\
\text { mate. }\end{array}$ & $\begin{array}{l}\text { Policultivo } \\
\text { autoconsumo } \\
\text { e comércio } \\
\text { (grãos, cereais, } \\
\text { frutas, batata, } \\
\text { mandioca); } \\
\text { Extração e } \\
\text { comércio de } \\
\text { madeira (cedro, } \\
\text { pinho); } \\
\text { Criação animais } \\
\text { de trabalho, } \\
\text { consumo e co- } \\
\text { mércio (suínos/ } \\
\text { banha). }\end{array}$ & $\begin{array}{l}\text { Monocultivo de } \\
\text { grãos e cereais; } \\
\text { Produção in- } \\
\text { dustrializada de } \\
\text { suínos e aves; } \\
\text { Policultivo para } \\
\text { autoconsumo e } \\
\text { comércio (milho, } \\
\text { mandioca, fru- } \\
\text { tas, leite, ovos). }\end{array}$ \\
\hline $\begin{array}{l}\text { Modo de } \\
\text { artificialização } \\
\text { do meio }\end{array}$ & $\begin{array}{l}\text { Apropriação } \\
\text { direta (caça, } \\
\text { pesca e } \\
\text { coleta); } \\
\text { Agricultura } \\
\text { de coivara. }\end{array}$ & $\begin{array}{l}\text { Sistema de culti- } \\
\text { vo de derrubada } \\
\text { e queimada. }\end{array}$ & $\begin{array}{l}\text { Sistema de ro- } \\
\text { tação de terras } \\
\text { melhorada com } \\
\text { tração animal } \\
\text { leve e pesada; } \\
\text { Crescente } \\
\text { especialização } \\
\text { da produção. }\end{array}$ & $\begin{array}{l}\text { Uso contínuo e } \\
\text { intensivo da ter- } \\
\text { ra com insumos } \\
\text { externos (fertili- } \\
\text { zantes, pestici- } \\
\text { das, "sementes } \\
\text { melhoradas"); } \\
\text { Motomecaniza- } \\
\text { ção parcial. }\end{array}$ \\
\hline
\end{tabular}

(Continua) 


\begin{tabular}{|c|c|c|c|c|}
\hline $\begin{array}{l}\text { Período } \\
\text { Variáveis }\end{array}$ & $\begin{array}{l}\text { Sistema } \\
\text { Indígena } \\
\text { (até1890) }\end{array}$ & $\begin{array}{c}\text { Sistema Caboclo } \\
(1890-1930)\end{array}$ & $\begin{array}{c}\text { Sistema } \\
\text { Colonial } \\
(1930-1970)\end{array}$ & $\begin{array}{l}\text { Sistema Atual } \\
\text { (a partir de } \\
\text { 1970) }\end{array}$ \\
\hline $\begin{array}{l}\text { Elementos } \\
\text { sociais chave }\end{array}$ & Indígenas. & $\begin{array}{l}\text { Caboclos (mis- } \\
\text { cigenação entre } \\
\text { luso-brasileiros, } \\
\text { hispano-ameri- } \\
\text { canos, negros e } \\
\text { indígenas). }\end{array}$ & $\begin{array}{l}\text { Predomínio de } \\
\text { colonos de ori- } \\
\text { gem europeia; } \\
\text { Caboclos em } \\
\text { menor propor- } \\
\text { ção. }\end{array}$ & $\begin{array}{l}\text { Agricultores } \\
\text { familiares; } \\
\text { Agricultores } \\
\text { empresariais; } \\
\text { Proletários } \\
\text { rurais. }\end{array}$ \\
\hline Acesso à terra & Coletivo. & $\begin{array}{l}\text { Coletivo com } \\
\text { parcelas } \\
\text { individuais (sem } \\
\text { regulamentação). }\end{array}$ & $\begin{array}{l}\text { Privado (regula- } \\
\text { mentado); } \\
\text { Unidades em } \\
\text { torno de } 20 \text { ha. }\end{array}$ & $\begin{array}{l}\text { Privado (regula- } \\
\text { mentado); } \\
\text { Unidades de } \\
\text { 15ha (média); } \\
\text { Arrendamento. }\end{array}$ \\
\hline $\begin{array}{l}\text { Aspectos } \\
\text { da força de } \\
\text { trabalho }\end{array}$ & $\begin{array}{l}\text { Livre; } \\
\text { Organização } \\
\text { tribal. }\end{array}$ & $\begin{array}{l}\text { Livre; } \\
\text { Mutirões para } \\
\text { coleta de erva } \\
\text { mate. }\end{array}$ & $\begin{array}{l}\text { Livre (familiar); } \\
\text { Mutirões. }\end{array}$ & $\begin{array}{l}\text { Livre (familiar e } \\
\text { contratada); } \\
\text { Escassez de mão } \\
\text { de obra. }\end{array}$ \\
\hline $\begin{array}{l}\text { Instrumentos } \\
\text { e equipa- } \\
\text { mentos de } \\
\text { produção }\end{array}$ & $\begin{array}{l}\text { Manuais } \\
\text { (machado } \\
\text { de pedra, } \\
\text { enxó, arco e } \\
\text { flecha, lan- } \\
\text { ça, canoa). }\end{array}$ & $\begin{array}{l}\text { Basicamente o } \\
\text { uso de machado, } \\
\text { foice, facão. }\end{array}$ & $\begin{array}{l}\text { Equipamen- } \\
\text { tos (macha- } \\
\text { do, serrote, } \\
\text { saraquá, foice, } \\
\text { facão, enxada, } \\
\text { arado de tração } \\
\text { animal); } \\
\text { Carroças e } \\
\text { galpões de ar- } \\
\text { mazenamento. }\end{array}$ & $\begin{array}{l}\text { Motomecani- } \\
\text { zação (arados, } \\
\text { grades, colhedo- } \\
\text { ras, semeado- } \\
\text { ras-adubadoras, } \\
\text { motosserra); } \\
\text { Equipamentos } \\
\text { manuais. }\end{array}$ \\
\hline $\begin{array}{l}\text { Excedentes } \\
\text { agrícolas }\end{array}$ & ------ & $\begin{array}{l}\text { Erva mate; } \\
\text { Eventualmente } \\
\text { produtos da } \\
\text { lavoura. }\end{array}$ & $\begin{array}{l}\text { Milho, feijão, } \\
\text { trigo, banha, } \\
\text { suínos. }\end{array}$ & $\begin{array}{l}\text { Soja, milho, tri- } \\
\text { go, suínos, leite } \\
\text { e derivados, } \\
\text { aves, fruticutura. }\end{array}$ \\
\hline $\begin{array}{l}\text { Fatores de } \\
\text { transição para } \\
\text { outro Sistema } \\
\text { Agrário }\end{array}$ & $\begin{array}{l}\text { Aumento } \\
\text { gradativo da } \\
\text { presença de } \\
\text { caboclos. }\end{array}$ & $\begin{array}{l}\text { Colonização ofi- } \\
\text { cial do território; } \\
\text { Privatização das } \\
\text { terras. }\end{array}$ & $\begin{array}{l}\text { Esgotamento } \\
\text { da fertilidade } \\
\text { do solo; } \\
\text { Crescimento } \\
\text { demográfico; } \\
\text { Saturação das } \\
\text { áreas disponí- } \\
\text { veis. }\end{array}$ & $\begin{array}{l}\text { Esgotamento da } \\
\text { terra e dos re- } \\
\text { cursos naturais e } \\
\text { impossibilidade } \\
\text { de substituí-los } \\
\text { por insumos/ } \\
\text { tecnologias } \\
\text { exógenos. }\end{array}$ \\
\hline
\end{tabular}

Fonte: Elaborado pelos autores (2017).

O sistema de cultivo praticado era o da coivara, que consistia na derrubada e queimada da mata para posterior semeadura/plantio. Cada parcela de terra era cultivada de dois a três anos, nos quais o solo, altamente fertilizado pelas cinzas da biomassa queimada na etapa anterior, propiciava uma produção bastante satisfatória. Em seguida, a parcela era deixada em pousio, isto é, sem nenhum tipo de manejo agrícola por dezenas de anos, permitindo a recomposição da mata num nível próximo do original. Após esse período, a floresta (biomassa), praticamente toda recomposta, era novamente derrubada e queimada, garantindo a renovação da fertilidade do solo. Durante as décadas de pousio, outras parcelas eram sucessivamente abatidas, queimadas, cultivadas e, posteriormente, 
deixadas em pousio.

Os equipamentos e ferramentas utilizados eram manuais e artesanais (machado, enxó, arco e flecha, lança, canoa, entre outros), produzidos de modo rudimentar com madeira, pedras e fibras vegetais. Tais instrumentos permitiam derrubar a densa floresta do Médio Alto Uruguai em parcelas de não mais que um hectare (MACHADO, 2001). A força de trabalho era livre e organizada pelas tribos, sendo o acesso à terra coletivo. A produção era inteiramente destinada ao autoconsumo.

A abundante disponibilidade de terras com vegetação adensada por densas florestas, associada à baixíssima densidade populacional, permitia que o tempo necessário para a recomposição da biomassa vegetal fosse plenamente assegurado. Sendo assim, a capacidade de renovação da fertilidade do solo era superior à necessidade dessas populações. Tratava-se, portanto, de um sistema agrário que não apresentava indícios de esgotamento do ecossistema explorado. No Médio Alto Uruguai, o sistema agrário indígena foi predominante até o final do século XIX, momento em que se constata um aumento significativo da presença de caboclos na região.

\subsection{Sistema agrário caboclo (1890-1930)}

Ao final do século XIX, a colonização europeia da metade norte do Rio Grande do Sul, sobretudo a colonizada por alemães e italianos, estava em franca expansão. Terras cada vez mais distantes dos polos demográficos e econômicos mais dinâmicos da época - Porto Alegre e Pelotas - começavam a ser ocupadas por colonos oriundos tanto de países europeus quanto das colônias velhas ${ }^{7}$ do Estado. Nesse processo, terras até então praticamente inabitadas foram sendo "ocupadas" com colônias organizadas, legitimadas pelo Estado. Contudo, ainda que com uma baixa densidade populacional, grande parte da metade norte do Rio Grande do Sul era habitada por tribos indígenas e populações caboclas ${ }^{8}$. Do ponto de vista étnico, esta população cabocla tem origem em um longo processo de miscigenação entre luso-brasileiros, hispano-americanos, indígenas e ex-escravos (afrodescendentes).

Em decorrência da expansão do processo de colonização, essas populações caboclas, assim como as populações indígenas remanescentes, foram sendo deslocadas para regiões ainda não colonizadas e cada vez mais distantes. A região ocupada pelos municípios do entorno de Frederico Westphalen somente receberia as primeiras levas organizadas de colonos a partir de 1920. Sendo assim, no período compreendido aproximadamente entre 1890 e 1920, a população da área hoje pertencente aos municípios de Frederico Westphalen, Caiçara, Iraí e Vicente Dutra era predominantemente cabocla. Esses sujeitos viviam nas matas e

\footnotetext{
${ }^{7}$ Referente às primeiras colônias de alemães e italianos, entre as quais se destacam São Leopoldo (alemã, iniciada em 1824) e Caxias do Sul (italiana, iniciada em 1875).

${ }^{8}$ Os documentos e a literatura referem-se a estes sujeitos de diversas formas: lavradores nacionais, caboclos, intrusos, sertanejos, mestiços, entre outros (ZARTH, 2000).
} 
na beira dos rios, obtendo seu sustento de diversas atividades, como caça, coleta, agricultura e venda de serviços.

Contudo, a característica essencial e comum entre essas populações tradicionais, que permite analisá-las enquanto grupo social (tratado aqui como "os caboclos"), consiste no fato de manterem relações econômicas com o mercado, de modo que não viviam isolados; "ao contrário, a possibilidade de sobrevivência desses homens livres no interior de densos maciços florestais da fronteira agrícola implicava em algum tipo de relação comercial com o mercado" (TAGLIETTI, 2005 , p. 6). A essa característica essencial dos caboclos acrescenta-se outro componente comum da identidade cabocla: o fato de serem completamente ignorados, por parte do Estado, no processo de colonização - pelo menos até a década de 1940, na região em questão (OLKOSKI, 2002).

Em relação ao tipo de agricultura praticado pelos caboclos (e, portanto, o tipo de agricultura predominante nesta região no final do século XIX e início do século XX), tratava-se de um sistema bastante semelhante ao praticado pelas populações indígenas, baseado na agricultura de coivara. Entretanto, constata-se uma crescente redução do tempo de duração do pousio florestal no sistema de cultivo de queimada. A explicação para esta situação decorre do paulatino aumento da densidade populacional na região, não somente pelo crescente número de novos caboclos como, posteriormente pela chegada e instalação de colonos. O destino da produção agrícola continuava a ser a subsistência, basicamente com as mesmas culturas produzidas pelos indígenas.

Em relação aos instrumentos de produção, as ferramentas empregadas eram basicamente o machado, o facão, a foice e, em menor grau, a enxada (TAGLIETTI, 2005), constituindo-se como instrumentos mais eficientes que os instrumentos indígenas. Quanto ao acesso à terra, este se dava através de parcelas individuais, ainda que de forma desregulamentada. Ao mesmo tempo, identificam-se parcelas coletivas, a exemplo dos ervais de erva-mate nativa, nos quais muitas vezes eram realizados mutirões para a atividade da colheita. Logo, caracterizava-se também um tipo diferente de organização social, no qual a força de trabalho dos caboclos e de suas eventuais famílias era aplicada ora nas parcelas individuais, ora nas atividades coletivas.

Cabe destacar novamente, conforme Olkoski (2005), a importância das relações comerciais que estas populações caboclas estabeleciam com outros grupos sociais através da troca do excedente de erva-mate (e outros produtos eventualmente coletados ou produzidos que pudessem ser comercializados ou trocados, como ervas medicinais, couro de animais silvestres, aves, madeira, etc) e pela inserção esporádica no mercado de trabalho, vendendo seus serviços para as companhias colonizadoras que passaram a atuar na região, as quais demandavam braços para a abertura de picadas e estradas. Esses eram os meios dos quais o caboclo dispunha para adquirir suprimentos básicos não produzidos localmente (querosene, sal, tecidos, etc.) nos centros de comércio mais próximos (BONETTI, 1998 apud REICHERT, 2008).

O esgotamento e crise deste sistema agrário tem sua centralidade no au- 
mento considerável da densidade populacional no território dos quatro municípios, a partir de 1920, em decorrência da atribuição da totalidade das terras agrícolas aos colonos. Tecnicamente, a possibilidade de praticar agricultura de coivara se esgota à medida que a densidade populacional (e, portanto, demanda por mais áreas agrícolas e por alimentos/produtos agrícolas) se eleva a tal ponto que supera a capacidade de recomposição da floresta e consequente renovação da fertilidade do solo, condição indispensável para a manutenção do sistema de cultivo de derrubada-queimada.

Inicialmente, ao se depararem com uma floresta densa e pouco penetrável, os imigrantes praticaram a agricultura de coivara em seus lotes. Contudo, devido a pequena dimensão dos lotes recebidos pelos colonos ${ }^{9}$, ainda menores que os 25 hectares estabelecidos oficialmente na época, a possibilidade de reprodução deste modo de agricultura logo se esgotou, obrigando os agricultores a adotarem um novo sistema de cultivo, baseado no trabalho mecânico do solo. Por fim, destaca-se que os caboclos foram os mais afetados com a privatização das terras no momento da chegada dos imigrantes, restando àqueles que não abandonaram a região áreas reduzidas e pouco férteis. Segundo Taglietti (2005, p. 6), o caboclo tinha muita dificuldade em "conviver e assimilar o sistema agrícola de produção do migrante de 'origem'", o que, entre outros motivos, fez com que sofresse um intenso abalo cultural com a chegada dos colonos.

\subsection{Sistema agrário colonial (1930-1970)}

A partir das décadas de 1920 e 1930, o processo de migração de colonos na região é consideravelmente intensificado. Apesar de sua matriz cultural comum (europeia), tais colonos tinham diferentes origens: eram russos, poloneses, alemães, italianos e, principalmente, teuto e ítalo-brasileiros oriundos das colônias "velhas" do Rio Grande do Sul. Nos primeiros anos, os colonos passaram a praticar, necessariamente, um modo de agricultura muito parecido ao praticado pelos caboclos. Foram inclusive tachados e tratados com desprezo por alguns dos principais pesquisadores da época - como Waibel (1958) e Roche (1969), apud Bublitz (2010, p. 46), por estarem praticando uma agricultura "caboclizada", considerada por eles uma regressão cultural. O que parece ter passado despercebido para tais autores é o fato de que o sistema de derrubada-queimada se mostrava como a única alternativa frente à densa floresta que estes colonos encontravam sobre seus lotes no momento da instalação. Mesmo após a queima inicial do mato derrubado, as raízes perduravam no solo por anos - muitas delas por décadas - impedindo grandes variações no manejo do solo, pelo menos nos anos

\footnotetext{
${ }_{9}^{9}$ Os colonos passaram a receber lotes de aproximadamente 20, por vezes de apenas 15 hectares, em razão da região já estar fortemente ocupada por caboclos, o que impedia ou pelo menos dificultava - a plena repartição das terras pela companhia colonizadora (OLKOSKI, 2002). A elevada população de caboclos na região do Médio Alto Uruguai (especialmente nos municípios em questão) foi propiciada pelo fato de que, durante o processo de colonização do RS, os caboclos foram sendo deslocados de diversas regiões para os últimos territórios ainda não ocupados pelos imigrantes.
} 
iniciais. Entretanto, pelo fato das áreas disponíveis para o cultivo serem diminutas, não tardou para que os colonos percebessem o crescente esgotamento da fertilidade do solo, fazendo com que alterassem o sistema de cultivo.

Esse novo sistema de cultivo, emblemático e característico do novo sistema agrário que rapidamente tomou forma nesta região, consistia basicamente no preparo mecânico do solo (aração e escaridificação superficial), rotação meIhorada de terras, tendo, inicialmente, o esterco dos animais e, posteriormente, também o cultivo de leguminosas como alternativas para a fertilização do solo, substituindo o papel antes cumprido pela derrubada e queimada da biomassa florestal. A disponibilidade de novas ferramentas (enxada, serrote, saraquá, carroças para transporte, e, posteriormente, o arado escaridificador de ferro, além dos tradicionais machado, facão e foice) e o maior grau de conhecimento acerca da rotação de cultivos, aliado à fertilidade residual deixada por anos após a derrubada da floresta, proporcionou um melhor desempenho desse novo sistema de cultivo. Segundo Waibel (1979 apud BUBLITZ, 2010, p. 107-108), este foi denominado de sistema de rotação de terras melhorado, além de novos sistemas de cultivo, identificação, introdução e disseminação de novos sistemas de criação (galinhas, porcos, cavalos e vacas). Os animais eram criados para diversos fins: autoconsumo (carne, ovos, leite, couro), trabalho (tração e transporte), e, posteriormente, para comércio, com destaque para os suínos, dos quais, inicialmente, interessava a banha (produto extremamente valorizado na primeira metade do século XX), e, mais tarde, a carne.

Identifica-se, ao longo deste período, um importante processo de especialização da produção agrícola, especialmente com o cultivo do milho e a criação de suínos. Igualmente, identifica-se um aumento e diferenciação dos excedentes agrícolas. Em meados do século XX, a agricultura da região já apresentava excedentes consideráveis em produtos como milho, suínos, feijão, trigo e batata. Conterato e Schneider (2006, p. 161) destacam que nessa fase "[...] houve também a ampliação das áreas cultivadas nas propriedades em razão da necessidade de comercialização de volumes maiores de produção, bem como do aprofundamento das relações mercantis". Os autores mostram ainda que, com o aumento da produção, "[...] multiplicam-se as casas de comércio compradoras da produção originária das pequenas propriedades rurais, que, além da subsistência, incrementam a produção destinada ao comércio" (CONTERATO; SCHNEIDER, 2006 p. 161).

Assim, à medida que melhora a infraestrutura de transporte e se consolidam mercados consumidores e os canais de comercialização, a atividade agrícola, fortemente centrada no policultivo destinado ao autoconsumo, passa a voltar-se cada vez mais para o comércio. Salienta-se ainda que as trocas dos excedentes agrícolas, inicialmente por outros produtos (sal, açúcar, café, querosene, tecidos, etc.), passam a ser realizadas cada vez mais monetarizados.

No auge desse sistema agrário, a população da região era predominantemente composta por colonos e, com um menor contingente, por $\operatorname{caboclos}^{10}$. A

\footnotetext{
${ }_{10}$ Paradoxalmente, os caboclos eram tratados como "intrusos", inclusive pelos órgãos oficiais do governo na região, conforme mostra Olkoski (2002).
} 
estrutura fundiária era marcada pela predominância de pequenos lotes de terra de cunho privado, sendo o trabalho organizado e realizado em nível essencialmente familiar, com eventuais mutirões realizados nos próprios lotes dos agricultores.

Ainda na década de 50, o sistema agrário colonial começa a apresentar os primeiros sinais de crise e esgotamento em seus preceitos, ocasionados por dois fatores principais. Em primeiro lugar, destaca-se o esgotamento da fertilidade do solo, em decorrência de décadas de intensificação das atividades agrícolas e de uma redução da fertilidade natural das parcelas cultivadas mais acessíveis e em áreas mais planas. Em segundo lugar, tornavam-se cada vez mais escassas e de difícil acesso novas áreas agrícolas. Para Seyferth (1999, p. 290), “[...] as possibilidades de reprodução social eram restritas em virtude da continuidade dos assentamentos ao longo de quase todo o fluxo migratório". Além disso, o engessamento jurídico da privatização da terra restringia o trabalho do colono a sua unidade de produção, inferior a 25 hectares, conforme mencionado anteriormente. Acrescenta-se ainda o fato de que, após algumas décadas instaladas na região, as famílias de colonos se ampliavam, contribuindo ainda mais para o aumento da densidade populacional.

Se por um lado o crescimento das famílias era vantajoso do ponto de vista do aumento da mão de obra familiar disponível, por outro lado, exigia a ampliação das áreas cultivadas, e, consequentemente, intensificação das atividades agrícolas, contribuindo para o desgaste do solo. Além disso, outro problema consistia na divisão da unidade de produção entre os filhos das gerações seguintes. Se 25 hectares já eram insuficientes "[...] para proporcionar a um agricultor e a sua família um padrão de vida econômico e cultural decente", conforme indicado por Waibel (1949 apud SCHNEIDER, 2002, p. 9), o fracionamento da propriedade significava condições ainda menos favoráveis para a reprodução social dos filhos e suas famílias.

Dentro de tal cenário, os agricultores foram desenvolvendo mecanismos para minimizar os fatores adversos. Talvez o exemplo mais significativo e peculiar da região tenha sido a criação e multiplicação de cooperativas agrícolas, a partir da década de 50 , visando impedir a subordinação dos agricultores às tradicionais casas de comércio (Conterato; Schneider, 2006, p. 162). O elevado grau de associativismo entre os agricultores da região manteve-se presente desde então, formalizado através das cooperativas, assumindo diferentes formatos e propósitos nas décadas seguintes.

\subsection{Sistema agrário atual (a partir de 1970)}

O sistema agrário que sucedeu o sistema colonial está intimamente ligado ao processo de modernização da agricultura conhecido como Revolução Verde. Exaustivamente descrita na literatura ${ }^{11}$, a Revolução Verde transformou a realidade

\footnotetext{
${ }^{11}$ A esse respeito podem ser consultadas as obras de Graziano da Silva (1996) e Guimarães
} (1989), entre várias outras. 
agrária de muitas regiões do Brasil e do mundo na segunda metade do século XX, alcançando os mais longínquos rincões do planeta.

Do ponto de vista agronômico, o pacote tecnológico difundido pela Revolução Verde, baseado na utilização de fertilizantes industriais, pesticidas, sementes híbridas e motomecanização agrícola (tratores, arados, grades, semeadoras-adubadoras, colhedoras, pulverizadores, etc), solucionava - ainda que com graves impactos sociais e ambientais - o problema da reprodução da fertilidade do solo. Ao mesmo tempo, abria possibilidades jamais vistas para a especialização produtiva, com monoculturas motomecanizadas em vastas extensões de terra.

Rompia-se, assim, a relação até então intrínseca entre lavoura e pecuária, tendo em vista que a fertilidade dos solos deixava de depender do esterco (principal insumo natural até então), passando a ser garantida por insumos industriais. Por se tratar de uma solução exógena, padronizada, o pacote tecnológico poderia ser aplicado praticamente em qualquer área agricultável. Do ponto de vista técnico, o único empecilho para isso eram (e continuam sendo) as restrições à motomecanização da agricultura em terras com limitações e restrições (relevo demasiadamente declivoso ou solos pedregosos e rasos).

No Rio Grande do Sul, a forma de agricultura preconizada pela Revolução Verde se generalizou a partir da década de 60, sobretudo no planalto meridional, onde o pacote tecnológico pôde ser adotado em sua plenitude. Na região do Médio Alto Uruguai não aconteceu diferentemente. Da mesma forma, os agricultores deste território, fortemente incentivados pelo Estado, passaram a adotar o conjunto de técnicas preconizadas pela Revolução Verde, o que implicou em uma transformação dos sistemas de cultivo e do sistema agrário como um todo. Cabe destacar, porém, que o relevo fortemente ondulado que predomina nesta região, associado a solos frequentemente pedregosos e rasos, não permitiu a plena adoção da motomecanização. De qualquer maneira, isso não impediu a intensificação da especialização produtiva, a partir da década de 60, para "[...] fazer frente ao processo de fracionamento das propriedades, ao esgotamento da fertilidade dos solos e ao fechamento da fronteira agrícola estadual, entre outros aspectos" (CONTERATO; SCHNEIDER, 2006, p. 162).

Cabe salientar que a Revolução Verde chegou aos municípios de Frederico Westphalen, Caiçara, Iraí e Vicente Dutra apenas poucos anos após os primeiros sinais de crise no sistema agrário colonial, diferentemente do que ocorreu em outras regiões do RS, que tiveram que desenvolver "soluções caseiras" para arcar com as consequências do esgotamento do solo por um período mais longo. Isso ocorreu pelo fato da colonização desses municípios ter sido iniciada quase 100 anos após a chegada das primeiras levas de colonos alemães ao Rio Grande do Sul. Como consequência, o sistema agrário colonial não experimentou um período de crise prolongado.

No sistema agrário que tomou forma, a especialização produtiva passa a se estender a outras atividades além da criação de suínos, com destaque para as lavouras de milho e para o binômio trigo-soja. Tendo em vista que os sistemas de criação e cultivo praticados até então não sustentavam mais o mesmo padrão 
de vida dos colonos, a agricultura da região passou a se orientar cada vez mais pelo mercado, passando a cultivar a terra de modo intensivo e contínuo, o que foi permitido pela crescente utilização de insumos externos. Sendo assim, reduziuse a diversidade de cultivos e industrializou-se a criação de suínos e aves, cenário mantido até o período atual.

Apesar disso, mantiveram-se cultivos e criações para autoconsumo, ainda que em menor grau. Ocorreu também a redução do tamanho médio das unidades de produção devido ao seu fracionamento e devido aos limites naturais impostos à motomecanização, impossibilitando o processo de concentração fundiária através da anexação de propriedades vizinhas, ocorrido nas regiões que dispunham de condições mais propícias para a adoção da Revolução Verde, tanto em relação ao relevo quanto pelo capital acumulado pelos colonos que se destacavam (são exemplos os municípios de Passo Fundo, Carazinho, Soledade, entre outros).

Em relação às categorias sociais presentes nesse novo sistema agrário, os agricultores familiares continuam amplamente predominantes na região. Contudo, destaca-se o aparecimento de empresários e de proletários rurais. Destaca-se ainda o intenso êxodo rural, a partir da década de 70 , em razão da redução da demanda por mão de obra causada pela especialização produtiva.

Com o passar do tempo, a agricultura dos quatro municípios - assim como dos demais municípios com características semelhantes no entorno - foi se tornando economicamente enfraquecida, acarretando baixos índices de desenvolvimento socioeconômico. Esse empobrecimento está relacionado à incapacidade da agricultura local de inserir-se plenamente no agronegócio, expressão que sintetiza hoje o modelo dominante de agricultura preconizado pela Revolução Verde no século passado. Essa incapacidade, por sua vez, está relacionada à impossibilidade - aparentemente crônica - da agricultura local de produzir em larga escala devido à estrutura fundiária de pequenas propriedades, a despeito do elevado grau de associativismo que permanece na região até hoje.

Sendo assim, a atividade agrícola que tem apresentado algum desempenho satisfatório na região é a produção de suínos e aves, adequada a pequenas propriedades familiares, porém subordinando-as às grandes empresas privadas. A impossibilidade de intensificação das lavouras de soja, milho e outros cultivos tem causado, inclusive, o abandono ou subutilização de áreas produtivas dentro das unidades de produção, identificando-se na paisagem local áreas em diferentes estágios de recomposição da vegetação, a exemplo dos "capoeirões".

Por fim, outra característica marcante no período atual é uma relativa baixa produtividade agrícola. Apesar de um importante aumento da produtividade agrícola, a partir da década de 1970 em especial, em decorrência de um progressivo aumento na utilização de insumos externos (adubos químicos, agrotóxicos), constata-se que a baixa escala de produção e a adoção parcial dos preceitos da Revolução Verde (em especial uma motomecanização parcial) afetam de maneira significativa o desempenho econômico e produtivo da agricultura local. 


\section{Considerações finais}

A reconstituição da evolução da agricultura dos municípios de Frederico Westphalen, Iraí, Caiçara e Vicente Dutra permitiu colocar em evidência uma série de situações marcantes. Em primeiro lugar, percebe-se que nas três primeiras etapas históricas, representadas pelos sistemas agrários indígena, caboclo e colonial, foram predominantemente protagonizados por grupos sociais de diferentes origens culturais: primeiramente pelos Caigangues, primeiros habitantes da região, seguidos pelo elemento extremamente miscigenado do caboclo e, por fim, pelos colonos de origem europeia.

Entretanto, apesar de possuírem diferentes costumes, crenças, línguas, constituindo culturas extremamente distintas, tinham em comum o fato de que todos tiveram que se adaptar às condições naturais da região para garantir sua sobrevivência através da agricultura. Mas, se por um lado os três grupos enfrentaram a necessidade de derrubar a densa floresta para cultivar o solo, por outro, o fizeram em momentos distintos, com intensidades e ferramentas distintas, sob uma organização social e uma lógica de acesso à terra distinta, elementos que conformaram sistemas agrários distintos.

Outro traço marcante foi o período de tempo extremamente reduzido em que as transformações e mudanças ocorreram nesta região. Isso ocorreu pelo fato de que a evolução dos sistemas agrários nesta região não foi fruto do processo histórico de um só povo e seu lento processo de acúmulo de conhecimento sobre a agricultura. Em outras palavras, o sistema agrário Indígena e, posteriormente, o sistema agrário caboclo não foram sucedidos por um sistema agrário desenvolvido por eles próprios, após uma eventual decadência do sistema de cultivo de derrubada-queimada. No momento da chegada dos colonos europeus, apesar da concentração de populações caboclas na região, o sistema de derrubada-queimada não passava por uma crise que exigisse sua superação. Tal crise viria com a elevação da densidade populacional pela chegada dos colonos e a consequente saturação das áreas disponíveis, superando a capacidade de renovação da floresta.

Contudo, pode se dizer que a crise na transição do sistema de cultivo de derrubada-queimada para o sistema de cultivo baseado na rotação de terras meIhorada não causou um grande abalo a agricultura da região, uma vez que os colonos já tinham conhecimento deste último, seja nas colônias das quais vieram, seja nos seus países de origem. Sendo assim, à medida que acabava o mato em seus lotes, os colonos (e também os caboclos, que passaram a dispor de áreas reduzidas) passavam a implantar este "novo" sistema de cultivo.

Também foi curto o período de transição do sistema agrário colonial para o sistema agrário atual, tendo em vista que os sinais de crise do primeiro (em razão do esgotamento da fertilidade do solo) surgiram pouco tempo antes da chegada da Revolução Verde. Nesta transição para um novo sistema agrário, da mesma forma que a transição anterior (do sistema caboclo para o colonial), destaca-se o fato de que novamente não foram os agricultores que, após experimentar o declínio de seu tipo de agricultura, desenvolveram novas formas de 
cultivo. A Revolução Verde, conforme apontado anteriormente, foi uma solução completamente exógena, uma receita literalmente importada. Em suma, pode-se afirmar que, em pouco mais de um século, a região abrangida pelos municípios em questão vivenciou os sistemas de cultivo que se desenvolveram e se sucederam na Europa ao longo de milhares de anos, conforme extensivamente descrito por Mazoyer e Roudart (2001).

A terceira característica que merece destaque diz respeito ao perfil de agricultores da região, extremamente heterogêneo e miscigenado, diferenciando-se fortemente do de outras regiões do Rio Grande do Sul. Conforme mostrado, essa heterogeneidade tem origem na elevada concentração de indígenas e, principalmente, de caboclos que precederam à chegada dos colonos. À medida que o território passava a ser ocupado por novos grupos sociais, estes adquiriam hábitos e costumes dos grupos anteriores, que se encontravam melhor adaptados ao ambiente local.

Assim, em cada novo sistema agrário que se conformava, permaneciam traços dos anteriores. A diversidade e miscigenação de culturas que daí se originou permanecem na região até os dias de hoje. Inclusive, podemos percebê-las nos nomes dos quatro municípios estudados: Iraí (palavra de origem indígena que significa "águas do mel", devido à abundância desse produto no local na época da colonização); Vicente Dutra (nome de origem portuguesa, em homenagem ao antigo intendente/prefeito do então município de Iraí); Caiçara (palavra que se refere às comunidades, sobretudo litorâneas e pescadoras, que nasceram da miscigenação de portugueses e indígenas, ou seja, caboclos); e, ainda, Frederico Westphalen (nome de origem alemã, em homenagem ao antigo chefe da Inspetoria de Terras da região).

Quanto às perspectivas para o futuro, a região não parece apresentar elementos nem condições naturais que permitam a superação da atual estagnação de sua realidade agrária. A incapacidade de inserção plena da agricultura da região no sistema preconizado pela Revolução Verde parece resguardar à realidade agrária dos municípios em questão uma posição periférica no modelo de agricultura dominante no Brasil. Aliado a isso, está o fato de que, aparentemente, a Revolução Verde ainda não chegou ao seu limite. Apesar das crises que esporadicamente afetam a agricultura, e mesmo que possamos prever drásticas consequências ambientas e sociais ligadas à expansão desse modelo, do ponto de vista técnico, a Revolução Verde tem conseguido se renovar, superando continuamente as debilidades técnicas que obstaculizam a atividade agrícola com o passar do tempo. Basta recorrer a exemplos como o desenvolvimento do plantio direto, as sementes transgênicas, a agricultura de precisão, entre outros que certamente ainda surgirão.

Sendo assim, resta aos agricultores e gestores da região buscar alternativas condizentes com a estrutura agrária, o perfil familiar das unidades de produção, a falta de mão de obra causada pelo êxodo e as limitações do relevo da região na tentativa de permitir um novo ciclo de ascensão da agricultura nesses municípios. 


\section{Referências}

BUBLITZ, J. Forasteiros na Floresta Subtropical: uma história ambiental da colonização europeia no Rio Grande do Sul. 2010. Tese (Doutorado) - Programa de Pós-Graduação em História Social, Universidade Federal do Rio de Janeiro, Rio de Janeiro, 2010.

CARNEIRO, D. M. Perfil Sócio Econômico e Crescimento versus Distribuição de Renda nos Três Coredes de menor PIB per capita do Rio Grande do Sul nos anos 2000. Porto Alegre: Coreconrs, 2011. Disponível em: <www.coreconrs.org.br>. Acesso em: 26 jul. 2012.

CONTERATO, M. A.; SCHNEIDER, S. A agricultura familiar do Alto Uruguai, RS: mercantilização e estratégias de reprodução no município de Três Palmeiras. Cadernos de Ciência \& Tecnologia, Brasília, v. 23, n. 2/3, p. 151-189, maio/dez. 2006.

CONTERATO, M. A.; SCHNEIDER, S.; WAQUIL, P. D. Desigualdades Regionais de Desenvolvimento Rural do Rio Grande do Sul: uma proposta de análise multidimensional a partir de três microrregiões. In: IV Encontro de Economia Gaúcha, Porto Alegre: FEE/PUCRS, 2008.

EMBRAPA. Empresa Brasileira de Pesquisa Agropecuária. Brasil em Relevo. 2005. Disponível em: <www.relevobr.cnpm.embrapa.br>. Acesso em: 6 jul. 2012.

GUIMARÃES, A. P. A crise agrária. 3. ed. Rio de Janeiro: Paz e Terra, 1989.

MACHADO, R. T. Análise Sócio Econômica e Perspectivas de Desenvolvimento para os Produtores de Leite do Município de Crissiumal - RS. Dissertação (Mestrado em Desenvolvimento Rural) - Universidade Federal do Rio Grande do Sul, Porto Alegre, 2001.

MATZENAUER, R. et al. Regime Anual e Estacional de Chuvas no Rio Grande do Sul. In: Congresso Brasileiro de Agrometeorologia, 15., 2007. Aracajú. Anais do XV Congresso Brasileiro de Agrometeorologia. Aracajú, 2007.

MAZOYER, M.; ROUDART, L. História das Agriculturas do mundo: do neolítico à crise contemporânea. Lisboa: Instituto Piaget, 2001.

MIGUEL, L. (Org.) A. Dinâmica e diferenciação de sistemas agrários. Porto Alegre: UFRGS, 2009.

OLKOSKI, W. A Questão Agrária no Médio Alto Uruguai: o processo de demarcação das terras. Revista de Ciências Humanas, Frederico Westphalen, ano VI, n. 6, p. 143-157, 2005.

OLKOSKI, W. História Agrária do Médio Alto Uruguai - RS: colonização, (re)apossamento das terras e exclusão (1900-1970). 2002. Dissertação (Mestrado em História) - Universidade do Vale do Rio dos Sinos, São Leopoldo, 2002.

REICHERT, P. Diferenças culturais entre caboclos e teuto-brasileiros de Porto Novo: a segregação social do caboclo. 2008. Dissertação (Mestrado em Geografia) - Universidade Federal do Rio Grande do Sul, Porto Alegre, 2008. 
SCHNEIDER, S. A atualidade da contribuição Leo Waibel ao estudo da agricultura familiar. Boletim Gaúcho de Geografia, Porto Alegre, v. 28, n. 1, p. 25-41, 2002.

SEYFERTH, G. A Colonização Alemã no Brasil: etnicidade e conflito. In: FAUSTO, B. (Org.). Fazer a América: a imigração em massa para a América Latina. São Paulo: EDUSP, 1999. p. 273-314.

STRECK, E. V. et al. Solos do Rio Grande do Sul. Porto Alegre: Emater/RS-Ascar, 2008.

TAGLIETTI, D. B. Um Olhar Sobre o Elemento Nacional no Período da Colonização da Região do Média Alto Uruguai - RS - 1917/1950. Revista de Ciências Humanas, Frederico Westphalen, ano VI, n. 6, p. 61-69, 2005. 